\title{
BENTUK AJARAN CATUR GURU DI SEKOLAH DASAR NEGERI 11 SANUR KECAMATAN DENPASAR SELATAN KOTA DENPASAR
}

Oleh:

Ni Nyoman Ari Lastini

Sekolah Dasar Negeri 6 Sanur

Ni Made Anggreni

Institut Hindu Dharma Negeri Denpasar

madeanggreni74@gmail.com

\begin{abstract}
Abstrak
Sekolah adalah salah satu tempat yang konsisten memberikan pendidikan kepada siswanya baik itu pendidikan pada sikap keagamaan, sikap sosial, intelektual serta keterampilannya. Siswa sebagai generasi muda sebagai penerima ilmu pengetahuan dari berbagai pihak harus memiliki disiplin guru bhakti. Terdapat empat unsur yang sangat penting dalam pendidikan disebut Catur Guru yang terdiri dari Guru Rupaka, Guru Pengajian, Guru Wisesa, dan Guru Swadhyaya.
\end{abstract}

\section{Kata Kunci: Catur Guru; Pendidikan Dasar}

\section{PENDAHULUAN}

Perubahan zaman tidak bisa dihindari, arus globalisasi yang begitu cepat merasuk ke dalam masyarakat terutama di kalangan generasi muda ini membawa pengaruh yang cukup kuat. Pengaruh globalisasi tersebut telah membuat generasi muda kehilangan kepribadian dan jati diri mereka sebagai bagian dari bangsa Indonesia. Kehilangannya mental kepribadian dan jati diri ini ditunjukkan dengan gejala-gejala yang muncul dalam kehidupan sehari-hari anak muda sekarang. Demikian pula Maksum (2016:227228) menyatakan bahwa globalisasi tidak dapat disangkal lagi, telah menghasilakan perubahan-perubahan mendasar dalam kehidupan manusia. Hampir seluruh sektor kehidupan tersentuh oleh pengaruh globalisasi, baik langsung maupun tidak langsung baik dalam perkembangan politik, ekonomi, kebudayaan, agama, dan pendidikan.

Globalisasi sendiri saat ini telah melanda seluruh belahan dunia, tak terkecuali Indonesia khususnya Pulau Bali. Kini, globalisasi telah menjadi ancaman tersendiri bagi budaya Bali serta sikap dan perilaku generasi muda Bali. Hal tersebut tercermin dari ketidakmampuan generasi muda masa kini dalam kegiatan-kegiatan yang berbau keagamaan, misalnya mejejahitan, membuat canang, metanding banten, membuat klakat dan sebagainya. Generasi muda Bali masa kini, cenderung lebih pintar mengoperasikan gadget/handphone ketimbang membuat sampian gantung, menyusun gebogan, atau sekedar mengulat tipat. 
Pendidikan diharapkan dapat mentrasfer sifat-sifat Ketuhanan yang ada dalam diri para peserta didik. Itulah sebabnya guru disebut sebagai rupavarjitha (ru) yang artinya mampu menyeberangkan orang lain dari lautan sengsara. Disinilah letak fungsi, peran, tugas, dan tanggungjawab yang tersulit dari seorang guru. Untuk memiliki kualifikasi seperti itu seorang guru harus melakukan sadhana disiplin spiritual yang ketat dan sungguhsungguh (Donder, 2008:110).

Selanjutnya menurut Undang-Undang Sisdiknas Tahun 2003 (Tim Penyusun, 2010:15) menyebutkan bahwa pendidikan adalah usaha sadar dan terencana untuk mewujudkan suasana belajar dan proses pembelajaran agar peserta didik secara aktif mengembangkan potensi dirinya untuk memiliki kekuatan spiritual keagamaan, pengendalian diri, kepribadian, kecerdasan, akhlak mulia, serta keterampilan yang diperlukan dirinya, masyarakat, bangsa dan Negara.

Pemaparan tentang pendidikan di atas dijelaskan bahwa pengembangan potensi anak untuk memiliki kekuatan spiritual keagamaan, pengendalian diri, kepribadian menjadi lebih ditonjolkan, karena dengan dasar spiritual keagamaan, pengendalian diri, kepribadian peserta didik akan dapat berkembang menguasai ilmu pengetahuan serta mampu memanfaatkan ilmu yang dimiliki untuk kepentingan masyarakat, bangsa, dan negara Indonesia. Sehingga jelas bahwa arah dan strategi pendidikan nasional adalah terbinanya manusia-manusia Indonesia yang bertaqwa kepada Tuhan Yang Maha Esa, dengan memperhatikan aspek-aspek

kecerdasan, keterampilan, dan keahlian.

Sekolah (lembaga pendidikan formal) merupakan lembaga yang berpengaruh besar terhadap pembentukan kepribadian setelah peran keluarga. Menurut Lestari (2014:35) sekolah tidak hanya mengedepankan kualitas akademik, tetapi tidak kalah penting juga adalah membangun karakter anak didik. Apa artinya memiliki anak cerdas, tapi suka berbohong, tidak jujur, serta berani kepada orang tua dan guru. Harapan kedepan, sekolah dapat menghasilkan kualitas sumber daya manusia yang handal, baik secara iman dan taqwa maupun ilmu dan teknologi (iptek). Perlu membangun kultur sekolah dengan landasan yang kokoh, yaitu karakter. Karakter di sini menyangkut nilainilai moral agama dan kecerdasan anak yang menjadi modal dalam masyarakat dan berbangsa.

Suksesnya pendidikan tidaklah lepas dari seorang guru yang memiliki kompetensi profesional guru yang meliputi seorang guru harus mampu menguasai bahan pembelajaran dan menguasai bahan pendalaman. Guru harus memahami dan melaksanakan pengembangan peserta didik. Guru juga harus menampilkan keteladanan dalam pembelajaran.

Berbicara perihal guru secara utuh sesungguhnya tidak dapat dipisahkan dengan konsep Catur Guru, dan Guru Swadhyaya (Tuhan) sebagai sentralnya. Sebagai umat manusia, maka menghormati Catur Guru merupakan hukum tertinggi. Adalah sangat mulia jika sejak awal telah tertanam dalam hati dan kepercayaannya bahwa ibu dan 
ayahnya adalah Tuhan itu sendiri (Donder, 2008:123).

Namun tidak dapat dihindari, secara perlahan-lahan masyarakat khususnya generasi muda mengikuti perkembangan zaman karena pengaruh globalisasi. Sehingga menjadi pertanyaan masih mampukah generasi muda meneruskan tradisi ini sebagai kewajibannya dengan berbagai fenomena ketidakmampuan generasi muda dalam kegiatan-kegiatan yang berbau keagamaan. Oleh sebab itu sangatlah penting menerapkan bentuk-bentuk ajara Catur Guru pada kehidupan siswa di SDN 11 Sanur.

\section{PEMBAHASAN}

\subsection{Catur Guru Bhakti Landasan Moral Spiritual}

Rasa bhakti dalam ajaran Catur Guru ini menegaskan penting dan agungnya peran dan fungsi guru dalam perjalanan pendidikan seseorang generasi muda. Keberhasilan pendidikan seseorang sangat ditentukan oleh guru. Disamping kekuasaan Tuhan sebagai Guru Swadhyaya, kualitas Guru Wisesa, Guru Pengajian, dan Guru Rupaka yang kemudian disebut dengan Tri Guru sangat besar pengaruhnya terhadap keberhasilan seseorang.

Tiga pilar pendidikan menurut Ki Hajar Dewantara adalah keluarga, sekolah, dan masyarakat (Mulyana dalam Wibawa, 2005:171). Sedangkan dalam agama Hindu tiga pilar pendidikan itu dinamakan "Tri Kang Sinangguh Guru” yang berarti tiga yang dinamakan guru. Ketiga guru itu adalah orang tua yang disebut Guru Rupaka, guru sekolah atau Guru Pengajian dan masyakarat dalam hal ini pemerintah yang dinamakan Guru Wisesa (Suhardana, 2010:5).

Diantara ke empat guru ada tiga guru yang populer dalam masyarakat karena bentunya nyata dan memberikan pembinaanpembinaan serta pendidikan yaitu: Guru Rupaka, Guru Pengajian, dan Guru Wisesa, sedangkan Guru Swadhyaya (Tuhan Yang Maha Esa) sifatnya abstrak dan sulit dirasakan oleh panca indra namun ajaran Beliau dapat dipahami melalui Kitab Suci maupun fenomena alam yang terjadi dalam kehidupan ini.

Di era teknologi informasi dan komunikasi di antara ketiga guru itu sesungguhnya tidak bisa dikatakan yang satu lebih berpengaruh atau lebih tinggi kedudukannya dari yang lain karena peranan dan fungsinya yang saling komplementer. Bersinerginya tri guru merupakan faktor penting penentu peningkatan kualitas pendidikan. Guru Wisesa/pemerintah memainkan peran penting dalam mengembangkan visi, misi, tujuan, strategi, kebijakan, rencana, dan program kerja yang jelas bagi penyelenggaraan pendidikan di seluruh tanah air. Guru Pengajian mendapat penghormatan karena Guru Pangajian adalah guru yang tidak hanya memberikan kesejahtraan jasmani, tetapi ia yang memberikan kebahagiaan rohani yang disebut dharma, yaitu pendidikan suci berupa kebajikan dan kesucian pribadi (Puniatmaja, 1992:49).

Rasa bhakti terhadap Catur Guru di SDN 11 Sanur dapat mempengaruhi karakter siswa yang baik untuk transfer nilai dan juga dapat meneruskan tradisi yang sudah ada. Selain itu, juga dapat mengembangkan sumber daya 
manusia Hindu yang unggul dalam berbagai bidang karena memiliki dasar yang kuat dalam bidang intelektual, emosional, dan spiritual yang bernafaskan rasa bhakti dari ajaran Catur Guru. Tentu dengan generasi muda yang unggul, mimpi ataupun harapan untuk memiliki generasi muda Hindu yang berkualitas dan memimpin kita akan dapat terwujud serta terealisasikan.

Kata bhakti berasal dari bahasa Sansekerta yang berarti bagian, dinding, kesetiaan, kecintaan, ketaatan, kepatuhan, kepercayaan, pelayanan, penyerahan diri dengan tulus ikhlas, serta kasih sayang (Surada, 2007:240). Bhakti adalah pernyataan cinta, sayang, sujud kepada sesuatu yang lebih dihormati misalnya: Tuhan, Leluhur, sesama makhluk, dan lingkungan. Bhakti muncul karena adanya Sradha terhadap Catur Guru, apalagi keyakinan terhadap Guru Swadhyaya atau Ida Sang Hyang Widhi. Ajaran bhakti adalah ajaran yang mudah dilasanakan oleh semua orang. Bahkan orang miskin maupun orang kaya, orang pandai maupun orang yang kurang pengetahuan, dari berbagai profesi seperti petani, pedagang maupun pejabat semuanya bisa menempuh jalan bhakti ini.

\subsection{Bentuk Ajaran Catur Guru Dalam Kehidupan Siswa di SDN 11 Sanur}

Menurut Poerwadarminta (1981:122) menyatakan bentuk adalah 1) lengkung; letuk; lentur, 2) melengkung; berlekuk, 3) penolong bilangan bagi barang-barang yang berkeluk seperti cincin, busur, 4) bangun (seperti bulat, segitiga dan sebagainya), 5) wujud dan rupanya; 6) Cara (sistem) dan susunan (ketatanegaraan, perserikatan dan sebagainya), 7) Wujud (yang kelihatan), 8) rupa, susunan, dan gaya karangan, 9) rupa atau bangun sesuatu kata.

Demikian pula pengertian bentuk dalam penelitian ini dimaksudkan bahwa ajaran Catur Guru yang sudah diperoleh oleh siswa pada proses pendidikannya diwujudkan dalam bentuk pikiran, perkataan, serta tidakan dalam keseharian. Implementasi ini sejalan dengan ajaran susila dalam agama Hindu yaitu Tri Kaya Parisudha. Mulai dari pikiran yang baik akan muncul perkataan serta tindakan yang baik demi mewujudkan rasa cinta kasih dalam bentuk bhakti kepada Catur Guru.

\section{1) Bhakti Kepada Guru Rupaka}

Bentuk rasa bhakti siswa kepada Guru Rupaka dapat diwujudkan dengan selalu memohon izin demi kelancaran, membantu pekerjaan rumah khususnya membantu orang tua untuk memasak di sore hari, menyapu, dan memberi ternak makanan. Siswa menyadari bahwa hormat kepada orang tua merupakan kewajiban, karena merekalah guru pertama yang mengenalkan dunia dan memberi contoh serta keteladanan hidup.

Suhardana

(2010:36)

menyatakan tentang rasa bhakti kepada Guru Rupaka dapat diwujudkan dengan mengikuti dan melaksanakan nasehat dari orang tua, membantu orang tua dalam pekerjaan di rumah dengan senang hati, menjungjung tinggi nama baik dan kehormatan keluarga, memperhatikan kesehatan orang tua, menjaga orang tua ketika sakit, dan melaksanakan upacara Pitra Yajña sebagaimana mestinya. 


\section{Guru Rupaka memang}

memiliki kewajiban membesarkan anak, namun sebagai ungkapan terimakasih karena jasa Beliau. Jasa ini tidak bisa tergantikan atau dibayar dengan materi, maka anak juga memiliki kewajiban memberi rasa bhakti kepada Guru Rupaka walaupun dengan kekurangan dan kelemahan. Bhakti kepada Guru Rupaka akan menghantarkan kita pada sikap yang penuh percaya diri dalam menghadapi masalah apapun.

Demikian pula Yuli (2014) dengan mengutip pesan Baba sebagai berikut: "hanya kerendahan hati yang bisa membuat engkau layak menerima kesejahteraan, dan akhirnya menuntunmu mencapai divinity. Engkau juga harus selalu menghormati dan mematuhi orang tuamu dan menganggap pendidikan serta semua fasilitas yang mereka berikan sebagai hadiah mereka kepadamu. Banyak orang tua mengalami stres dan ketegangan untuk memberikan ini kepadamu. Kadang-kadang, mereka bahkan membayar semua biaya dan tagihan. Dalam kitab suci Taittiriya, 1.11 mätrdevo bhava, pitrdevo bhava, ächarya devo bhava, atithidevo bhava terjemahannya: seorang ibu adalah dewa, seorang bapak adalah dewa, seorang guru adalah juga dewa, dan para tamupun adalah dewa. Karaktermu yang baik akan dikenali hanya jika engkau rendah hati dan menghormati orang tuamu. Banyak orang telah menjalani nilainilai ini dengan cara yang mulia. Mereka yang menjalani kehidupan dengan kerendahan hati dan ketaatan kepada orang tua akan mencapai sukses besar dalam semua bidang kehidupan".

Kewajiban seorang anak adalah memberikan penghormatan yang sangat tinggi kepada orang tua. Seperti pernyataan di atas bahwa dalam kitab suci Taittiriya sudah jelas dikatakan bahwa ayah dan ibu merupakan perwujudan Tuhan di dunia. Selain itu orang tua yang disebut dengan Guru Rupaka merupakan orang yang telah melahirkan manusia ke bumi ini. Sehingga wajib hukumnya bagi seorang anak untuk menghormati orang tuanya. Namun banyak contoh dalam kehidupan ini yang patut dijadikan pedoman untuk melaksanakan bhakti kepada Guru Rupaka agar terhindar dari alpaka guru.

Dalam kitab suci Sarasamuscaya 246 disebutkan ada empat pahala yang diterima oleh anak-anak yang berbhakti kepada orang tua, berikut terjemahannya: "Akan phala hormat bhakti terhadap orang tua, adalah empat jenis hal yang bertambah, perinciannya: kirti, ayusa, bala, yaca; kirti artinya pujian tentang kebaikan, ayusa artinya hal hidup, bala artinya kekuatan, yaca artinya peninggalan yang baik (jasa) itulah yang bertambah sempurna sebagai pahala hormat bhakti terhadap orang tua" (Kajeng, 2010:196).

Memaknai bunyi sloka tersebut, sangat beruntunglah bila seorang anak selalu berbhakti terhadap orang tua. Seorang anak yang berbhakti akan selalu mendapatkan pujian dan didoakan untuk mendapatkan keselamatan oleh keluarga. Mendapatkan kehormatan dan kekuatan yang positif sebagai kemampuan untuk memecahkan masalah-masalah kehidupan. Sloka ini dapat dijadikan pedoman bagi siswa untuk selalu berbhakti pada orang tua karena akan menjadi 
contoh bagi keturunan selanjutnya di dalam keluarga.

\section{2) Bhakti Kepada Guru Pengajian}

Guru Pengajian adalah guru yang memberikan kita pendidikan secara formal di sekolah berdasarkan aturan-aturan yang dikeluarkan oleh pemerintah. Syarat pertama yang harus dimiliki oleh seorang guru pengajian adalah ijazah guru. Seorang guru diwajibkan berpendidikan serendah-rendahnya sarjana pendidikan guru, agar memiliki profesi untuk mendidik, mengajar dan melatih siswanya di sekolah berdasarkan kurikulum yang ada sebagai dasar dan pedoman dalam memberikan pendidikan secara formal (Tim Penyusun, 2014:56).

Pada masa menuntut ilmu atau dalam agama Hindu disebut dengan masa Brahmacari, kewajiban pokok yang harus dilakukan adalah belajar ilmu pengetahuan dan keterampilan, serta menatapkan kematangan jiwa dalam mendalami ajaran agama Hindu. Hal ini dinyatakan dalam kutipan Lontar Putra Sesana Lampiran 2-3 berikut ini:

"anwam pweki wayahnya yogyan ika lekasa mengaji, haywa tar pepet, tan haroharoikang manah, twi taman mengawe-angen len sakeng aji, apan nirmala budhining si suta, tan hana wisaya kacita denika, apan yan duweging wayah katilinging wisaya, malina buddhi cancala ..........."

Terjemahan:

Adapun ketika masih muda, sepatutnya diutamakan untuk belajar jangan lalai dan bimbang dalam pikiran. Janganlah memikirkan hal- hal lain. Kecuali ilmu pengetahuan, sebab pada masa suci bersih pikiran si anak, belum terpengaruh oleh nafsu. Dan jika ulat mengendalikan indria pada waktu remaja, maka lenyaplah kekacauan itu. Dan yang perlu diperhatikan dalam hidup berguru atau menuntut ilmu itu, di mana setiap orang menjalani hidup brahmacari diwajibkan menaati peraturan-peraturan yang berlaku antara lain: seorang brahmacari tidak boleh makan banyak, makannya dua kali sehari dengan tidak berlebihan. Ia tidak boleh makan apa-apa diantara jam makan pertama dan makan kedua karena itu mengganggu kesehatan dan memperpendek umur. Ia harus bangun pagi-pagi sebelum gurunya bangun, dan ia tidur malam setelah gurunya tidur, ia tidak boleh hidup berfoya-foya, tidak boleh memakai wangi-wangian dan tidak boleh bersuka-ria, ia harus hidup sederhana, jujur tidak akan berbicara yang tidak bermanfaat dan mengerang nafsu diri sendiri seperti marah, loba kama, dan sebagainya. Jadi menurut sistem pendidikan Hindu kesederhanaan dan kejujuran dengan berlatih yang berat dengan cara yang umum. Yang menjadi tugas dan kewajibannya adalah hanya mengisi diri dengan ilmu pengetahuan yang disebut dharma. Bentuk bhakti dari siswa yang masih dalam tingkatan brahmacari kepada Guru Pengajian adalah dengan cara melakukan dharma sebagai seorang siswa-siswi di sekolah

Berbhakti kepada Guru Pengajian merupakan kewajiban seorang siswa dalam proses aguronguron. Seorang anak dituntun dan diajarkan ilmu pengetahuan suci, dibina dan dididik agar memiliki 
pengetahuan sebagai bekal menjalani hidup dalam melaksanakan Brahmacari. Seorang anak dilahirkan secara spiritual oleh Guru Pengajian melalui pengetahuan suci, sehingga segala kegelapan yang dimiliki mampu dihilangkan dengan ajaran suci yang cemerlang.

Sudipta (2016) menyatakan bila seorang siswa yang berbhakti dengan Guru Pengajian mendapatkan anugerah dan jalan yang terbaik dalam hidupnya. Kisah tentang bhakti seorang siswa dengan Guru Pengajian dapat dilihat dari kisah Sang Bima yang tanpa ragu melaksanakan perintah gurunya, yaitu Bhagawan Drona untuk pergi ke tengah samudra mencari Tirtha Amrta. Walaupun penuh dengan tantangan, cobaan dan bahaya yang mengancam, tetapi Sang Bima mampu mendapatkan anugerah karena rasa bhakti terhadap gurunya. Begitu juga tentang kisah bhakti seorang siswa dengan gurunya dapat dilihat pada kisah Bhagawan Dhomya yang memiliki 3 (tiga) orang siswa yang bernama Sang Arunika, Sang Utamanyu, dan Sang Weda. Ketiga siswanya diuji melalui tugas yang diberikan oleh Bhagawan Dhomya. Sang Arunika ditugaskan untuk mengerjakan sawah, Sang Utamanyu ditugaskan memelihara lembu dan Sang Weda ditugaskan bekerja di dapur menyiapkan makanan untuk persembahan dan sedekah. Dengan penuh rasa bhakti dan tulus ikhlas ketiga muridnya melaksanakan tugas yang diberikan, maka ketiga muridnya itu mendapatkan anugerah yang luar biasa dari gurunya. Itulah wujud bhakti seorang siswa kepada gurunya yang digambarkan pula oleh Panca Pandawa yang sebelum berperang melawan Korawa memohon anugerah kepada gurunya, yaitu Bhagawan Drona, sehingga Panca Pandawa memenangkan perang.

Mewujudkan rasa bhakti kepada Guru Pengajian dengan cara yaitu: menyapa dan memberi hormat kepada guru, mentaati peraturan sekolah atau tata tertib sekolah, tepat waktu dalam menjalankan tugas yang diemban, serta selalu melakukan perbuatan yang berbudi luhur. Merayakan hari HUT PGRI dengan melaksanakan upacara sebagai bentuk bhakti kepada guru yang telah membimbing dengan ilmu pengetahuan.

\section{c) Bhakti Kepada Guru Wisesa}

Guru Wisesa adalah pemerintah yang selalu berusaha mendidik dan mengayomi rakyatnya, selalu berusaha mensejahterakan dan memberikan pelindungan. Karena itu pemerintah harus selalu dihormati dan dihargai. Kita perlu mewujudkan rasa bhakti kita kepada pemerintah (Suhardana, 2010:37).

Seorang pemimpin harus mampu mengayomi masyarakatnya dan menjadi pelindung bagi rakyatnya, tetapi apabila ada pemimpin yang tidak melaksanakan kewajibannya menjadi tercela dan hilang wibawanya. Tugas sebagai pemerintah amat berat pula seperti yang dijelaskan di atas, sehingga berbhakti kepada Guru Wisesa (pemerintah) merupakan kewajiban masyarakat, karena sudah diberikan perlindungan, rasa aman dan juga kesejahteraan dalam hidup.

Sudipta (2016) menyatakan dalam Kitab Ramayana XXIV.61, disebutkan bahwa keharusan wibawa pelindung Negara yang akan dipujipuji, tetap di bibir rakyat dan jadi kenang-kenangan mereka. Demikianlah keharusan dan 
kewajiban seorang raja perwira, tetapi jika lari dari medan perang, nistalah, hinalah raja demikian. Itulah kewajiban seorang pemimpin bagi rakyatnya, dan kewajiban rakyat terhadap pemimpin adalah mematuhi segala peraturan (hukum dan undang-undang) yang ditetapkan sebagai wujud bhakti terhadap Guru Wisesa. Rakyat yang menghormati dan menjunjung tinggi wibawa pemimpinnya mendapatkan hidup yang bahagia, aman, nyaman, damai dan sejahtera.

Karakter penokohan Bhagawan Drona dan Bhagawan Bisma dalam epos Mahabarata, mengisahkan tentang bhakti terhadap Guru Wisesa. Bhagawan Drona dan Bhagawan Bisma dengan penuh rasa bhakti dan hormat kepada pemimpin (raja) serta bhakti terhadap Negara (Dharma Negara). Bhakti yang mereka lakukan sungguh mulia, sehingga mendapat anugerah yang luar biasa dan nama mereka tetap harum sepanjang zaman. Itulah bentuk bhakti kepada Guru Wisesa sebagai pemimpin yang perlu kita hormati dan patuhi.

Siswa mewujudkan rasa bhakti kepada pemerintah antara lain dengan cara: selalu menghormati aparatur pemerintah yang jujur dan bersih, memelihara dan menjaga harta benda milik pemerintah, cinta tanah air, Negara, dan Bangsa. Mereka melakukan kegiatan gotong royong setiap hari sabtu sebagai benduk rasa perduli dan cinta kasih terhadap lingkungan. Selain itu siswa juga menjaga buku-buku yang di biayai oleh dana BOS, di mana dana bantuan oprasional siswa itu berasal dari KAS Negara Indonesia. Bentuk bhakti kepada pemerintah dilakukan pula oleh siswa dengan mengimplementasikan ajaran
Pancasila sila ke-4. Realisasi ini nampak dengan cara mengadakan pemilihan pengurus kelas dan menghormati hhasil dari pemilihan tersebut.

\section{e) Bhakti Kepada Guru Swadhyaya} Bhakti kepada Tuhan merupakan alat yang paling baik untuk menjamin keberhasilan. Bhakti kepada Tuhan akan memberikan kesehatan yang baik, kemakmuran, dan kesejahteraan. Disamping itu bhakti kepada Tuhan juga akan menghilangkan kebencian dan kebinggungan serta memberikan kekuatan yang lebih baik kepada tubuh kita. Dengan berbhakti, seseorang akan selalu memuja Tuhan tanpa pikiran buruk dan ketidaktulusan. Bhakti juga akan dapat memenangkan berkah Tuhan, mampu meningkatkan kesehatan baik jasmani maupun mental. Bhakti juga menghilangkan kecemburuan dan kebencian (Suhardana, 2010:14).

Guru Swadhyaya disebut pula guru sejati. Dinamakan guru sejati karena Beliau adalah Ida Sang Hyang Widhi Wasa. Beliaulah yang telah menciptakan alam semesta dengan segenap isinya ini, kemudian memelihara, melindunginya, dan akhirnya juga melebur atau mengembalikan ke dalam bentuk asalnya. Dinyatakan sebagai guru karena Tuhan adalah pembimbing utama bagi umat manusia yang tidak ada bandingannya. Beliau Mahatau, Beliau juga Mahakuasa, dan Mahasakti. Karena itu sebagai manusia kita perlu mewujudkan rasa bhakti kita kepada Tuhan dengan sungguh-sungguh dan tulus ikhlas (Suhardana, 2010:36).

Sebagai umat Hindu kita meyakini adanya Ida Sang Hyang Widhi Wasa sebagai sumber dari 
segala kehidupan yang dapat kita jalankan. Beliaulah sebagai penuntun dalam kehidupan sehingga kita bisa selamat dalam melaksanakan segala kegiatan, karena seberapa pintarnya kita sebagai umat apabila beliau tidak berkenan, segala yang kita lakukan tidak akan mendapatkan hasil yang diharapkan. Hal itu dapat pula diawali dengan melakukan persembahyangan dengan menggunakan sarana upacara sebagai wujud korban suci yang tulus dan ikhlas (Tim Penyusun, 2014:65).

Melalui pelaksanaan yajña yang dilakukan baik itu setiap hari maupun sewaktu-waktu, maupun sembahyang sebelum melakukan suatu kegiatan, hal tersebut sematamata bertujuan agar Ida Sang Hyang Widhi memberikan rahmat-Nya sehingga hubungan yang harmonis akan tercapai. Hubungan yang dilakukan manusia kehadapan Ida Sang Hyang Widhi Wasa merupakan perwujudan rasa bhakti.

Demikian pula dalam kitab suci Bhagavad Gìtā III.9 terdapat ajaran tentang pelaksanaan bhakti yang diajarkan oleh Sri Krisna terhadap Arjuna berikut bunyi terjemahan sebagai berikut: "lakukanlah perbuatan-perbuatan sebagai persembahan suci kepada Tuhan Yang Maha Esa. Kalau tidak, perbuatan-perbuatan tersebut akan mengakibatkan ikatan karma di dunia ini. Oleh karena itu, wahai Arjuna..., lakukanlah segala perbuatan sebagai persembahan suci kepada Tuhan Yang Maha Esa, maka engkau akan dibebaskan dari segala ikatan karma" (Darmayasa, 2014:35).

Dari kutipan di atas, dapat dijelaskan bahwa kegiatan-kegiatan persembahyangan yang dilakukan seperti persembahan suci merupakan bentuk bhakti umat. Di mana setiap perbuatan yang dilakukan baik atau buruk, terikat oleh hukum karma. Sehingga disarankan kepada umat manusia untuk berbuat bhakti tanpa mengharapkan hasil demi kepentingan pribadi saja. Demikian halnya berbhakti kepada Guru Swadhyaya ditunjukkan dengan hubungan timbal balik antara manusia dengan Tuhan, manusia dengan manusia, dan manusia dengan lingkungan. Ketiga hubungan ini dalam agama Hindu disebut dengan ajaran konsep Tri Hita Karana.

Perwujudan rasa bhakti siswa kepada Guru Swadhyaya yang ditujukan oleh siswa dengan ngaturang canang setiap pagi secara bergilir dengan teman-teman, melakukan persembahyangan saat ada upacara keagamaan dan yang paling sering dilakuakn adalah melaksanakan puja tri sandhaya setiap pagi di halaman sekolah serta di kelas menjelang pelajaran ditutup.

Rasa bhakti dalam Catur Guru ini menegaskan penting dan agungnya peran dan fungsi guru dalam perjalanan pendidikan seseorang. Keberhasilan pendidikan seseorang sangat ditentukan oleh guru. Disamping kekuasaan Tuhan sebagai Guru Swadhyaya kualitas Guru Wisesa, Guru Pengajian, dan Guru Rupaka yang kemudian disebut dengan Tri Guru sangat besar pengaruhnya terhadap keberhasilan seseorang. Apabila seseorang dalam hidupnya tidak menerapkan ajaran Guru Bhakti, maka hidupnya diliputi dengan penderitaan, kesengsaraan, kesedihan, dan selalu dirundung dengan musibah serta malapetaka. Maka dari itu untuk mewujudkan kebahagiaan dalam hidup, hal yang 
mesti dilakukan adalah berbhakti kepada para guru. Seseorang yang selalu menanamkan rasa bhakti kepada para guru adalah mereka yang selalu terberkati, terlindungi, dan mendapatkan anugrah yang luar biasa. Guru sesungguhnya pelepas kegelapan dalam hidup yang mampu menuntun kearah cahaya kehidupan yang bahagia. Karena ajaran guru bhakti merupakan penuntun untuk mampu meraih dan mewujudkan kebahagiaan yang utama.

Dari pemaparan di atas dapat disimpulkan bahwa bentuk ajaran Catur Guru yang diterapkan dalam proses belajar di SDN 11 Sanur sesuai dengan teori struktural fungsional yang dikemukakan oleh Talcott Parsons. Talcott Parsons dalam Ritzer (2011:121) mengemukakan bahwa dalam teori fungsionalisme struktural, masyarakat mempunyai kelembagaan yang saling terkait dan tergantung satu sama lain. Dalam penelitian ini bentuk saling terkait dan tergantung ialah antara anak dengan orang tua, siswa dengan guru, masyarakat dengan pemerintah, dan seorang bhakta terhadap Tuhannya. Keterikatan ini diwujudkan oleh sisaw dengan cara mengamalkan ajaran bhakti kepada Catur Guru dalam kehidupan mereka.

\section{SIMPULAN}

Bentuk ajaran Catur Guru di SDN 11 Sanur diwujudkan dengan berbhakti kepada Catur Guru yaitu sebagai berikut: a) Bhakti kepada Guru Rupaka diwujudkan oleh siswa-siswi dengan melakukan adaptasi tentang keadaan keluarga; b) Bhakti kepada Guru Pengajian diwujudkan siswa-siswi dengan melakukan bhakti dengan cara memberi salam atau menyapa dan memberi rasa hormat kepada Ibu/Bapak Guru sebelum memulai pelajaran; c) Bhakti kepada Guru Wisesa diwujudkan oleh siswa-siswi dengan mengikut program literasi yang dikembangkan oleh Dinas Pendidikan; dan d) Bhakti kepada Guru Swadhyaya diwujudkan dengan cara melaksanakan puja Tri Sandhaya, berdoa sebelum memulai pelajaran, serta melalukan sembahyang bersama saat hari raya besar keagamaan.

\section{DAFTAR PUSTAKA}

Alih aksara Putra Sesana: Koleksi Pusdok.

Darmayasa. 2014. Bhagavad Gìtā (Nyanyian Tuhan). Denpasar: Yayasan Dharma Sthapanam.

Donder, I Ketut. 2008. Acarya Sista Guru \& Dosen Yang Bijaksana Perspektif Hindu. Surabaya: Paramita.

Kajeng, I Nyoman., Dkk. 2010. Sārasamuccaya. Surabaya: Paramita.

Lestari, Sri. 2014. Psikologi Keluarga. Jakarta: Kencana.

Maksum, Ali. 2016. Sosiologi Pendidikan. Malang: Madani. Poerwadarminta, W.J.S, 1987. Kamus Umum Bahasa Indonesia. Jakarta: Balai Pustaka.

Puniatmaja, I.B Oka. 1992. Panca Sradha. Jakarta : Yayasan Dharma Sarathi

Ritzer, Goerge., Douglas J. Goodman. 2004. Teori Sosiologi Modern. Jakarta: Prenada Media Group.

Sudipta, I Nyoman Agus. 2016. Guru Bhakti Jalan Menuju Kebahagiaan (http://phdi.or.id/artikel/guru- 
http://ejournal.ihdn.ac.id/index.php/AW

bhakti-jalan-menuju-

kebahagiaan), 29 Maret 2018.

Suhardana, K.M. 2010. Catur Guru

Bhakti Bhakti Kepada Empat

Guru Dilengkapi Sila

Kramaning Aguron-guron

dan Siwa Sarana. Surbaya: Paramita.

Surada, I Made. 2007. Kamus Bahasa SansekertaIndonesia. Surabaya:

Paramita.

Tim Penyusun. 2010. UndangUndang Republik Indonesia
Nomor 20 Tahun 2003.

Bandung: Citra Umbara.

Tim Penyusun. 2014. Pendidikan

Agama Hindu dan Budhi

Pekerti. Jakarta: Balitbang Kemdikbud.

Wibawa, Made Aripta. 2005. Siapakah Yang Disebut Guru? Panakom: Denpasar.

Yuli Santosa. 2014. (http://saijnana.blogspot.co.id /2014/05/thought-for-day-1stmay-2014-thursday.html), 29 Maret 2018. 